\title{
The efficiency of USG and age related formula to determine the endotracheal tube diameter in pediatric patient
}

Cerrahpasa Medical Faculty Anesthesiology and Reanimation Department, Istanbul University

A Cigdem Tutuncu, Meltem Kanar, Pinar Kendigelen, Guner Kaya

\section{ntroduction}

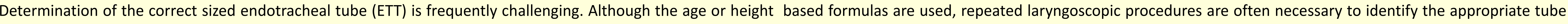

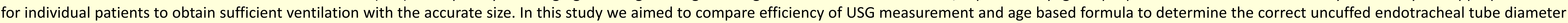
according to established tube diameter in clinically.

\section{Methods}

After the obtaining ethics comitee and parenteral informed consent. The patients from 2 to 10 years of age who were planned various type of surgeries were prospectivelly included this study. Exclusion criteries were patients weighted less than $10 \mathrm{~kg}$ or more than $50 \mathrm{~kg}$ and suspected laringeal and upper airway abnormalities. After the general anesthesia was induced by inhalation or intravenous way, the maintanance was provided with remifentanyl and sevoflurane with mask ventilation.

During the mask ventilation and end of the inspiration, interna transverse diameter of cricoid level was measured with ultrasonography in B mode with a linear probe placed on the midline of the anterior neck. The cricoid cartilage appereance was established with the arched, rounded hypoechoic structure and the hyperechoic air column width was measured as cricoid diameter The tube diameter was also calculated with Cole formula and noted for same patient. The neuromuscular blocker was administered and patients were entubated with the best fit endotracheal tube in clinically. The endotracheal tube (ETT) which was providing less than $30 \mathrm{~m}$ leaka with the $25 \mathrm{cmH}_{2} 0$ peak airway pressure and 6-8 $\mathrm{m} / \mathrm{kg}$ tidal volume during the ventilation was accepted the convient diameter and size. All patient characteristics, results from measurements, and the predicted OD cactented according to formulas 'ID [mm $=4+$ age [years]/4' for the specific tube to the formulas 'ID
were noted.

\section{Results}

The one hundred patients were enrolled the study Mean age was $4.24 \pm 1.85$ years. The succesful intubation rate at the first attempt was $87 \%$, the second attempt rate was $12 \%$, and only $1 \%$ patient need the third attempt. The mean diameter was obtained with Cole formula $(4.95 \pm 0.53 \mathrm{~mm})$ were smaller than the clinically fitted endotracheal tube diameters $(5.66 \pm 0.5 \mathrm{~mm})$. The mean cricoid diameter obtained with USG measurements $(8.32 \pm 0.98 \mathrm{~mm})$ were higher than the clinically fitted endotracheal tube diameters $(7.82 \pm 0.72 \mathrm{~mm})$. Correlation with clinical established ETT size and both formula and USG were showen in figure 1 and 2 .

Bland Altman analysis showed (figure 3 and 4) a mean bias of $0.71 \mathrm{~mm}$ with the limits of agreement (bias \pm 0.36 SD) 0.0012 to 1.42 for formula and a mean bias of 0.5 $\mathrm{mm}$ with limits of agreement (bias $\pm 0.73 \mathrm{SD}$ ) -0.93 to 1.93 for ultrasound.
Table 1. Comparision of the inner and outer diameters

\begin{tabular}{|l|l|l|l}
\hline & Clinically (mean \pm SD) & USG $($ mean \pm SD) & p \\
\hline Inner Diameter $(\mathrm{mm})$ & $5.66 \pm 0.50$ & $\mathbf{5 . 8 1} \pm 0.64$ & 0,001 \\
\hline Outer Diameter $(\mathrm{mm})$ & $7.82 \pm 0.72$ & $\mathbf{8 . 3 2} \pm 0.98$ & 0,001 \\
\hline & & & \\
\hline & Clinically (mean \pm SD) & Formula (mean \pm SD) & p \\
\hline Inner Diameter $(\mathrm{mm})$ & $5.66 \pm 0.50$ & $\mathbf{4 . 9 5} \pm 0.64$ & 0,001 \\
\hline Outer Diameter $(\mathrm{mm})$ & $7.82 \pm 0.72$ & $6.94 \pm 0.98$ & 0,001 \\
\hline & USG (mean \pm SD) & Formula (mean \pm SD) & $\mathrm{p}$ \\
\hline Inner Diameter $(\mathrm{mm})$ & $5.81 \pm 0.64$ & $\mathbf{4 . 9 5} \pm 0.64$ & 0,001 \\
\hline Outer Diameter $(\mathrm{mm})$ & $8.32 \pm 0.98$ & $\mathbf{6 . 9 4} \pm 0.98$ & 0,001 \\
\hline
\end{tabular}

Graphic 1. Comparision of the inner and outer diameters

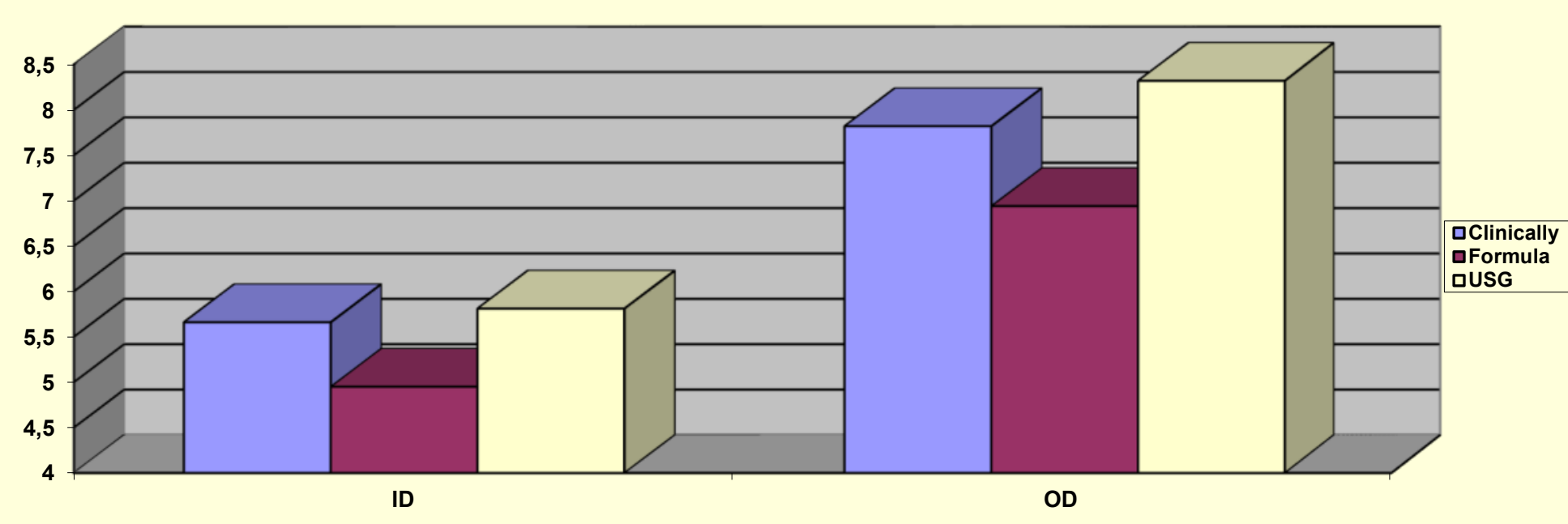

Figure 1: Correlation analysis of Cinically and USG diameter

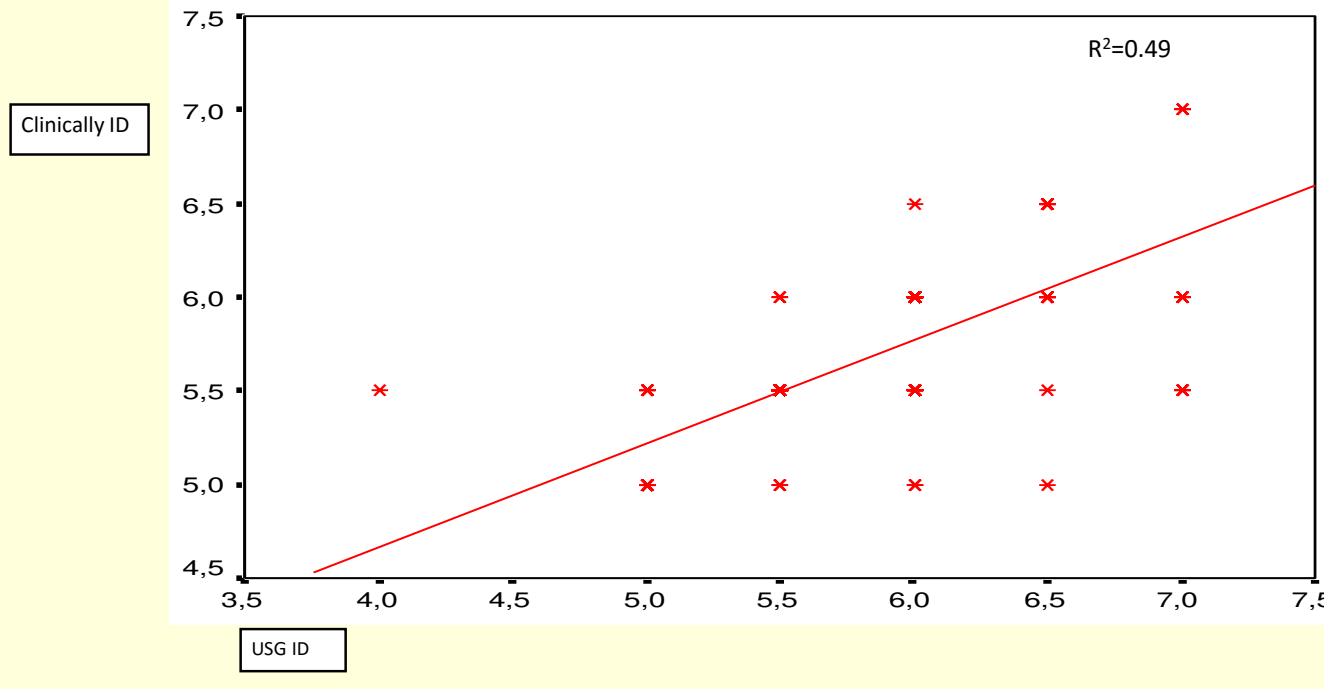

Figure 2: Correlation analysis of Cinically and Formula

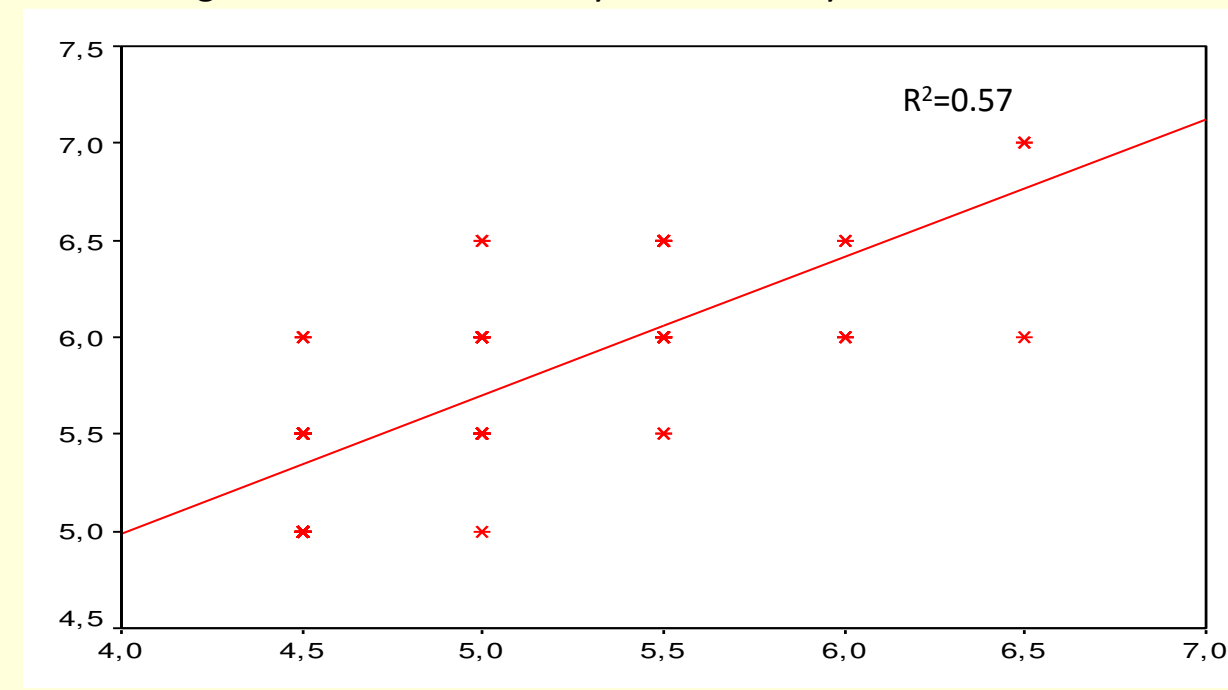

Formul ID
Figure 3: Bland-Altman analysis of Clinically versus Formula

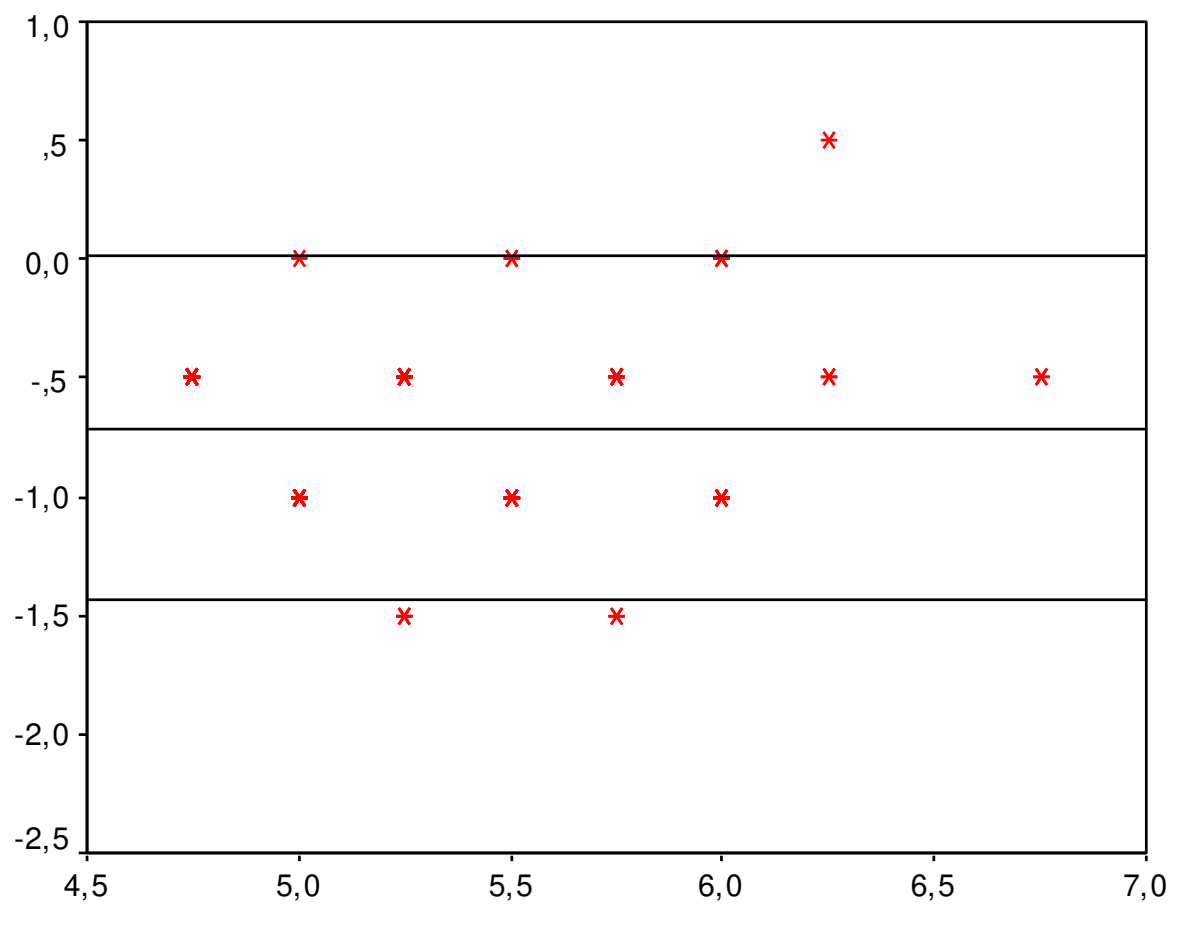

Average ID of Formula and Clinically

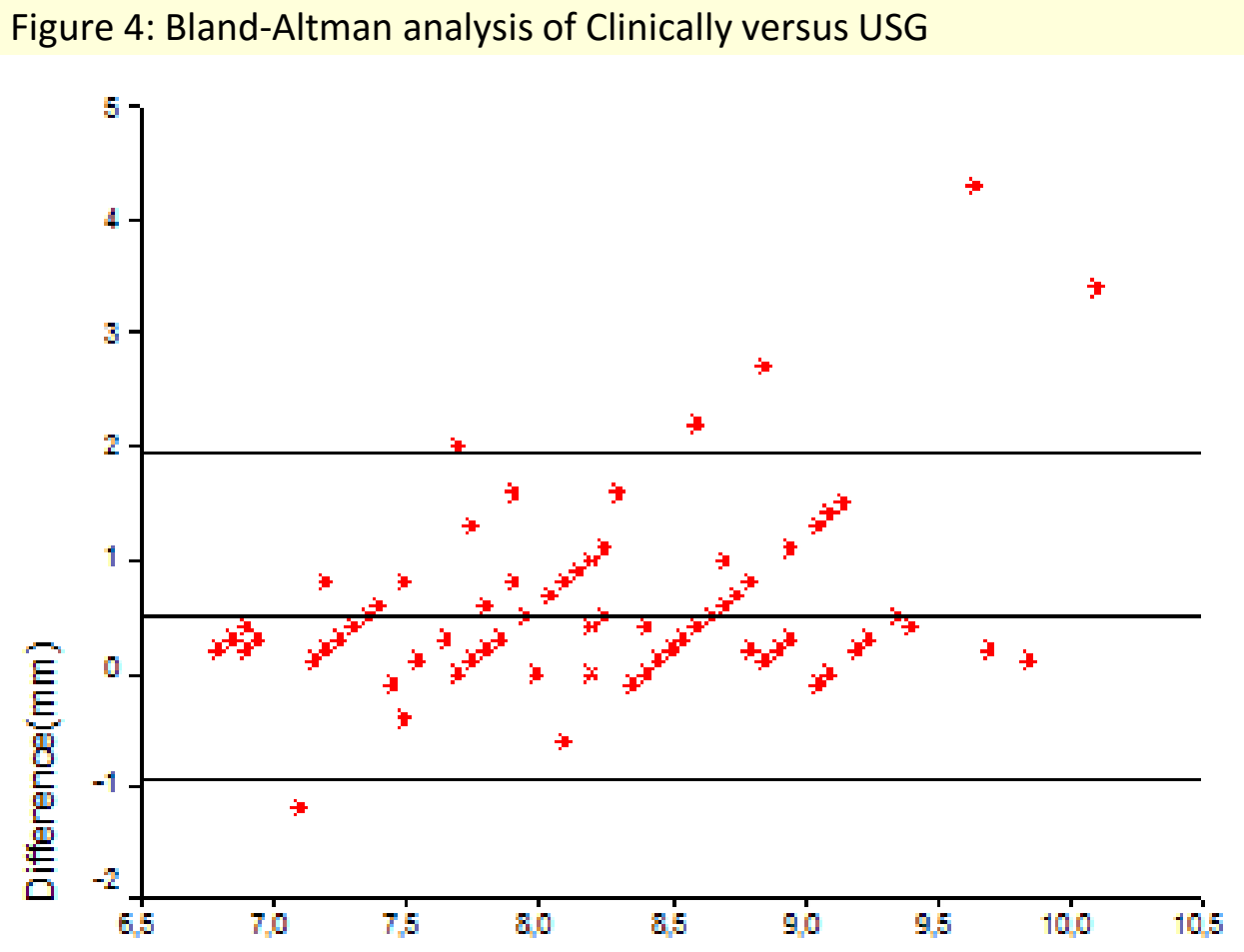

Average OD of USG and Clinically

\section{Discussion}

Measuring cricoid diameter with ultrasonography may provide prediction of the best fit ET size with $0.5 \mathrm{~mm}$ difference. The corrected $R^{2}$ value was 0.49 for USG and 0.57 for formula. The ratio of the appropiate endotracheal tube selection was reported between 47-77\% in previous studies with Cole formula. We found the similiar accuracy ratio, We reliazed that the formula provides smaller size than the clinically usage and the bigger ETT tube sizes are being measured with ultrasonography evaluations.

f 作 to determine the correct size. All these factors may affect that the ultrasound is not accuratelly reliable technique for exact ETT size. 